\title{
Antibody response of sheep to simultaneous vaccine administration of foot and mouth disease, blue tongue, peste des pestits ruminants, and sheep-goat pox antigens
}

\section{Beyhan Sareyyüpoğlu ( $\sim$ beyhan.sar@gmail.com )}

foot and mouth disease institute https://orcid.org/0000-0002-0279-1673

Veli Gülyaz

Harran Üniversitesi: Harran Universitesi

Fahriye Saraç

Veterinary Research Institute

Serdar Uzar

Veterinary Research Institute

Özden Kabaklı

Veterinary Research Institute

Can Çokçalışkan

Project Directorate on Foot and Mouth Disease

Ceylan Gündüzalp

Project Directorate on Foot and Mouth Disease

Eylem Aras Uzun

Project Directorate on Foot and Mouth Disease

Onur Çamlı

METU: Orta Dogu Teknik Universitesi

\section{Research Article}

Keywords: Antibody response, viruses, simultaneous, sheep, vaccination

Posted Date: September 28th, 2021

DOI: https://doi.org/10.21203/rs.3.rs-881466/v1

License: (c) (1) This work is licensed under a Creative Commons Attribution 4.0 International License. Read Full License 


\section{Abstract}

There are many infectious animal diseases in Turkey and generally vaccination is the prime control strategy to combat them. However, it is difficult to apply all vaccines in a definite period in the field due to limitations of the labor and finance. The rapid vaccination and effective use of labor can be possible with the help of simultaneous vaccines administrations. The aim of the study is to show the effects of simultaneous foot-and-mouth disease (FMD), peste des pestits ruminants (PPR), sheep-goat pox (SGP) and bluetongue (BT) vaccine administration on the antibody response of sheep. For this aim, 30 sheep were divided in to the one experiment and 5 control groups. Blood samples collected in each group at 30 and 60 days post-vaccination (DPV). Immune response was measured with virus neutralization test (VNT), liquid phase blocking ELISA (LPBE) for FMDV, VNT for BTV and PPR. A live virus challenge study was performed to determine the immune response of SGP vaccine. As a result, antibody titers for each vaccine agent decreased on $60 \mathrm{DPV}$ with the simultaneous vaccination. The difference between means of antibody titers with single and simultaneous vaccinations are significant especially for BTV and PPR vaccines at 60DPV $(p<0.05)$. It was concluded that four vaccines can not be used simultaneously in sheep.

\section{Introduction}

FMD is a highly contagious viral disease caused by Picornavirus. It affects all the cloven-hooved animals causing economic losses. SGP disease, which is a generalized viral infection in sheep and goats, leads to outbreaks. SGP virus is classified in the Poxviridae family (Kitching, 1986). The disease creates lesions in the skin and internal organs besides abortion, mastitis, and deaths in lambs and kids. Peste Des Pestits Ruminants (PPR) is an acute viral infection caused by the morbillivirus (OIE 2019). The disease is widespread in Africa, Arabian Peninsula, Middle East, and Turkey (Özkul et al. 2002). Blue Tongue (BT) is a viral disease of ruminants and transferred with flies. Virus is classified in the genus Orbivirus of the Reoviridae family. The disease is characterized by congestion, edema, and hemorrhage besides decreasing the fertility rate and causes significant economic losses (Maclachan 2011) .

Vaccination is the prime control strategy againt FMD, SGP, BT, and PPR in Turkey and other endemic countries (Özkul et al. 2002; Saagerman 2008; Perry and Rich 2007; Khorasani et al. 2016). The animals are injected simultaneously at different sites of the body during the simultaneous vaccine implementations. Since many factors affect immunity, the effect of simultaneous vaccine administrations (especially for two live vaccines) on immune response should be examined in detail (Trotta et al. 2015). The main considering factor should be interference when using live vaccines together. Since, during the interference, one viral vaccine agent suppresses the replication of another one which can cause inadequate immunity. The interference between different components of vaccines can result in very different immunological effects such as antigenic competition. It means that a vaccine antigen may lead to immune response decrease in the presence of the other antigen (Boikos et al. 2017; Tizard 2017). Another factor is the epitope sharing between the vaccine viruses, in that an increased or a decreased immune response may be observed in the organism (Dagan et al. 1998). Interactions of adjuvants among 
the vaccines during the vaccine co-administration can be possible other factor to consider (Fox et al. 2013). A live vaccine must replicate in an organism to show it's efficacy. In other words, it almost gives the same immune response as the natural immunity of its agent. The main mechanism is the stimulation of macrophage cells by the live antigen following the presentation of antigen to the T-lymphocyte cells and then the cellular and humoral immunity develop by the secretion of interleukins and other immune elements (Tizard 1990; Tizard 2017).

Rabies, swine fever, vesicular stomatitis, anthrax, Brucellosis, rinderpest, hemorrhagic septicemia, and parvovirus vaccines are used simultaneously with the FMD vaccine in the World (Trotta et al. 2015; Castenada et al. 1976; Joseph 1984; Hedger et al. 1986; De Clerq et al. 1989a; Srinavasan et al. 2001; Hancı 2016; Çokçalışkan et al. 2019; Gülyaz et al. 2019). In a study (Hedger et al. 1986), it was gained successful results in cattle with the simultaneous rinderpest and FMD vaccine administrations. In another study (De Clerq et al. 1989b), the interference was not observed with the simultaneous administration of IBR, adenovirus, and parainfluenza-3 vaccines. The result was favorable with the simultaneous vaccination of two modified live virus vaccines in pigs (Kristiensen et al. 2018). However, in contrast to these studies, in a research (Castenada et al. 1976), undesired results obtained with the simultaneous application of vesicular stomatitis and FMD vaccines. In Turkey, there are only three reports about simultaneous vaccine administration in veterinary field (Hancı 2016; Çokçalışkan et al. 2019; Gülyaz et al. 2019). The vaccines used in the present study are commercial vaccines routinely used in campaign vaccinations in Turkey. The simultaneous application of these vaccines will reduce the number of visits to farms and significantly decrease the labor force and cost used in the vaccinations. The immune response to the individual agents used in simultaneous vaccinations is generally positively affected or at least not changed by co-administration. For this purpose, this study aimed to determine the effect on the immune response of sheep against each of four vaccine agents when the SGP, BTV, PPR, and FMD vaccines were used simultaneously.

\section{Material And Methods}

\section{Vaccines}

TURVAC oil FMD vaccine, a trivalent, inactive, double oil emulsion with Montanide ISA 206 adjuvant, is produced by the FMD Institute in Ankara/Turkey. Live attenuated sheep goat pox (SGP) vaccine (PEST-S ETVAC) including at least DKID $5010^{4.5} / \mathrm{ml}$ pox virus is produced at istanbul Pendik Veterinary Research Institute in Turkey. Live attenuated PPR vaccine (PEST-S ETVAC) containing at least the DKID50 $10^{5} \mathrm{ml}$ strain of Nigeria 75/1 and live attenuated BTV vaccine (BLU T4 ETVAC) -strain of SA/BTV-4 against BTV4 serotype were used and they are produced at Ankara Etlik Veterinary Research Institute in Turkey.

\section{Animals And Immunisation Route}


A total of 30, sixth-months-old male FMD, BT, SGP, and PPR virus seronegative Merino sheep obtained from a state farm were used in the study. The animals were randomly divided into 6 groups (Table 1). To determine their seronegativity against FMDV, BTV, PPR and SGP; 0 . day sera of animals were analyzed against these agents via ELISA and VNT. Then, the animals were vaccinated subcutaneously against the four different agents at the same time at Pendik Veterinary Research Institute. A total of $1 \mathrm{ml} \mathrm{FMD}$ vaccine was administrated to the right pre-axillar region of animals and $1 \mathrm{ml}$ of each live vaccines (BT, PPR and SGP) were administrated with separate injection sites in the left side of the pre-axillar region. After collecting 30DPV blood sera, same day, sheep and goat pox virus challenge study was initiated. Blood samples were collected at 60DPV and 20 days after the live virus challenge study. Serum samples were stored at $-20^{\circ} \mathrm{C}$ until analyzed. All vaccinated sheep were monitored daily for the body temperature, lesion, and appetite during the study.

Table 1

Group of animals

\begin{tabular}{|lll|}
\hline Groups & & Number of animals $(\mathbf{n})$ \\
\hline 1 & FMD, SGP, PPR, BTV simultaneous vaccination & 10 \\
\hline 2 & FMD single vaccination (control) & 4 \\
\hline 3 & SGP single vaccination (control) & 4 \\
\hline 4 & PPR single vaccination (control) & 4 \\
\hline 5 & BTV single vaccination (control) & 4 \\
\hline 6 & Unvaccinated (negative control) & 4 \\
\hline
\end{tabular}

\section{Serological assays and live virus challenge study}

\section{Foot and Mouth Disease}

FMDV virus circulation of animals was determined as recommended by the kit with the day 0 sera (PRIOCHECK FMDV NS, The Netherlands) (Sorensen et al. 1998). To determine total antibody response of animals, LPBE was performed (OIE 2019; Hamblin et al. 1986). The protective cut-off titer of LPBE was accepted as $1 / 96$. VNT was performed for neutralizing antibody response (OIE 2019). Glasgow-MEM containing $50 \mu \mathrm{l}$ of Fetal Calf Serum (FBS-BIOWEST, France) were placed in all wells of a 96-well plate. 50 $\mu \mathrm{l}$ of the blood serum of each sheep was placed in the first four wells of the plate, and $50 \mu \mathrm{l}$ of the first wells were transferred to the lower wells to make the two-fold dilutions of the serum. FMD virus strains in $50 \mu \mathrm{l}$ of 100 DKID $_{50}$ were added to two-fold dilution of the serum samples in the wells and let to neutralize for one hour at $37^{\circ} \mathrm{C}$. At the end of the incubation period, $50 \mu \mathrm{l}$ of BHK21 cell culture was 
added to all wells and incubated in $5 \% \mathrm{CO}_{2}$ medium for 72 hours at $37^{\circ} \mathrm{C}$. Cells were checked daily for CPE and evaluated by staining with crystal violet (SIGMA-ALDRICH, USA) ${ }^{2}$. The protective cut-off titer of VNT was accepted as $1 / 22$ and $1 / 96$ for LPBE

\section{Sheep and Goat Pox}

To determine the antibody response of animals at day 0, VNT was performed. Every step almost similar to the FMDV VNT assay, but the main difference was at the end of the incubation period, $50 \mu \mathrm{l}$ of Vero cell culture was added to all wells and incubated in $5 \% \mathrm{CO}_{2}$ medium for 10 days at $37^{\circ} \mathrm{C}$. Cells were checked daily for CPE. To perform the live virus challenge study, SP(I)LK5 pathogen field strain was diluted ten fold and injected $0.2 \mathrm{ml}$ dose intradermal route four different sites of the abdomen of sheep (Group 1 and 3 ) in that it is placed $5 \mathrm{~cm}$ interval among the sites. Sheep were monitored daily for after 15 days during the live virus challenge study for body temperature, lesions, changes in the inoculation sites (OIE 2019).

\section{Peste Des Pestits Ruminants}

To determine the immune response of animals, VNT was performed (OIE 2019). A total of $80 \mu \mathrm{l}$ EMEM (GIBCO, USA) were placed in the first row of a 96-well plate. Then $50 \mu \mathrm{l}$ EMEM was added the other wells. $1 / 5$ dilution was prepared in the first row when the $20 \mu$ serum samples (each serum was worked in double-well). After that, $50 \mu \mathrm{l}$ of the first wells were transferred to the lower wells to make the two-fold dilutions of the serum. PPR virus of Nigeria $75 / 1$ strains in $50 \mu$ of 1000 DKID50 was added to two-fold dilution of the serum samples in the wells and let to neutralize for one hour at $37^{\circ} \mathrm{C}$. At the end of the incubation period, $50 \mu \mathrm{l}$ of Vero cell culture was added to all wells and incubated in $5 \% \mathrm{CO} 2$ medium for 12 days at $37^{\circ} \mathrm{C}$. Cells were checked daily for CPE The protective cut-off titer of VNT was accepted as $1 / 10$.

\section{Blue Tongue}

To determine the immune response of animals, VNT was performed (OIE 2019). A total of $90 \mu \mathrm{l}$ EMEM (GIBCO, USA) were placed in the first row of a 96-well plate. Then $50 \mu$ EMEM was added the other wells. $1 / 10$ dilution was prepared in the first row when the $10 \mu \mathrm{l}$ serum samples (each serum was worked in double-well). After that, $50 \mu \mathrm{l}$ of the first wells were transferred to the lower wells to make the two-fold dilutions of the serum. BT virus of SA/BT-4 strains in $50 \mu$ of 100-300 DKID50 was added to two-fold dilution of the serum samples in the wells and let to neutralize for one hour at $37^{\circ} \mathrm{C}$. At the end of the incubation period, $50 \mu \mathrm{l}$ of Vero cell culture was added to all wells and incubated in $5 \% \mathrm{CO} 2$ medium for days at $37^{\circ} \mathrm{C}$. Cells were checked daily for CPE. The protective cut-off titer of VNT was accepted as 1/10. 


\section{Statistical analysis}

Parametric and non-parametric statistical methods were used for independent samples with single and simultaneous vaccinations at 30DPV and 60DPV. The Shapiro-Wilk test, two sample t-test, and Wilcoxon rank sum test were performed to test the normality assumption for all samples. The proportion of protected animals with the single and simultaneous vaccination were compared to investigate the effect of SGP vaccine at $60 \mathrm{DPV}$ since the results of live virus challenge study are not quantitative. Z-test was used for the comparison of the proportions. $\mathrm{R}$ language and environment (R Development Core Team, 2020) was used to carry out all analyses in this study (Carey 2015).

\section{Results}

It was not found any seropositive animal after analyzing 0 . day sera against FMDV, BTV, PPR, and SGP. The mean antibody titers for FMDV, BT, and PPR on day 60 DPVs with the simultaneous and single vaccination groups were shown in Figures (Fig. 1a, 1b, 1c, and 1d). The mean antibody titers, standard errors and $p$-values for the significance of differences in mean antibody titers between the single and simultaneous vaccinations at 30 and 60DPVs are shown in Tables 2 and 3 , respectively. It can be concluded that the difference between means of antibody titers with single and simultaneous vaccinations are significant for BTV and PPR vaccines at 60 DPV $(p \leq 0.05)$. However, since the $p$-values are less than the significance level of 0.05 , the decision is to reject the null hypothesis. According to statistical results, a decrease of antibody titers was found statistically significant between the 30DPV and 60DPV especially for BTV and PPR vaccine agents ( $p<0.05$ ), (Tables 2 and 3 ). As for SGP vaccine, we can conclude that the proportion of protected animals (because of the live virus challenge study, the immune response of SGP vaccine was evaluated according to protected animal ratio in the population (n $=10$ ) is not significantly different between the single and simultaneous vaccination groups with a $p$ value $=0.1712$, which is greater than the significance level $a=0.05$. This may be as a result of small sample size in the group. It was also not determined any statistical importance between the single and simultaneous vaccination groups for FMD vaccine. 
Table 2

Mean and standard errors of antibody titers and p-values at 30 DPV

\begin{tabular}{|llll|}
\hline Vaccine agent/test method & Single vaccination & Simultaneous vaccination & p-value \\
\hline FMDV serotype O/ VNT & $1.73 \pm 0.47$ & $1.64 \pm 0.29$ & $>0,05$ \\
\hline FMDV serotype A/ VNT & $1.73 \pm 0.47$ & $1.41 \pm 0.24$ & $>0,05$ \\
\hline FMDV serotype 0/ LPBE & $2.02 \pm 0.14$ & $1.82 \pm 0.13$ & $>0,05$ \\
\hline FMDV serotype 0/ LPBE & $2.04 \pm 0.17$ & $2.06 \pm 0.14$ & $>0,05$ \\
\hline PPR/ VNT & $1.06 \pm 0.15$ & $0.71 \pm 0.11$ & $>0,05$ \\
\hline BTV /VNT & $1.06 \pm 0.15$ & $0.83 \pm 0.17$ & $>0,05$ \\
\hline All p-values are compared to signifiance level, $\mathrm{a}=0.05$. & \\
\hline
\end{tabular}

Table 3

Mean and standard errors of antibody titers and p-values at 60 DPV

\begin{tabular}{|llll|}
\hline Vaccine agent/test method & Single vaccination & Simultaneous vaccination & p-value \\
\hline FMDV serotype O/ VNT & $2.28 \pm 0.09$ & $1.68 \pm 0.25$ & $>0,05$ \\
\hline FMDV serotype A/ VNT & $2.43 \pm 0.08$ & $1.74 \pm 0.26$ & $>0,05$ \\
\hline FMDV serotype O/ LPBE & $2.28 \pm 0.26$ & $1.93 \pm 0.16$ & $>0,05$ \\
\hline FMDV serotype A/ LPBE & $2.32 \pm 0.25$ & $2.12 \pm 0.15$ & $>0,05$ \\
\hline PPR/ VNT & $1.36 \pm 0.15$ & $0.56 \pm 0.04$ & $<0,05$ \\
BTV/ VNT & $1.36 \pm 0.15$ & $0.60 \pm 0.08$ & $<0,05$ \\
\hline All p-values are compared to signifiance level, $\mathrm{a}=0.05$. & \\
\hline
\end{tabular}

\section{Discussion}

Vaccination is the main control strategy of FMD, BT, PPR, SGP diseases in Turkey. Simultaneous vaccinations help to increase work-speed, reduce labor and vaccination stress for the animals. In the present study, it was aimed to determine the effect on the immune response of sheep after the simultaneous SGP, BT, PPR, and, FMD vaccine administration. It was determined that simultaneous administration of above mentioned vaccines elicited adequate neutralizing and total antibody titers against the FMD vaccine, however, it was not provided sufficient immune response to three live attenuated vaccines (BTV, PPR and SGP), (Fig. 1a,b,c,d). Here, all of three live vaccines (BT, PPR, and SGP) were administrated in the left side of the pre-axillar region but FMD vaccine was the right side. This is one reason why FMD immune response not affected negatively. Since poxviruses are known to activate a wide variety of cellular proteins to escape host immune defense such as viral interleukins (IL-2,4,10). These cytokines suppress the cellular responses in various ways (Friebe et al. 2004; Gülyaz 2019). 
Especially the IL-10 is the most important anti-inflammatory cytokine which suppresses cellular responses in various ways. Therefore, the local interleukin-10 response probably suppressed the immune response of three vaccine agents except from FMD vaccine.

Similar to this study result, inadeqate immune response were obtained when the vaccines were simultaneously administrated in a few studies. Castenada (1976) has shown that low antibody titers were determined with the simultaneous vesicular stomatitis and FMD vaccinations. In another study (Ruben et al. 1973), measles seroconversion rates were decreased during the simultaneous administration of measles, smallpox, yellow fever vaccines In these studies, researchers reported that interference was responsible for the low antibody titers. There is only one research that used four vaccine agents together as with this study (Srinavasan 2001 ). However, in that study, all vaccine agents (FMD, rabies, Pasteurella, and Clostridium) were inactivated, combined formulation and they gained succesful result. FMD and anthrax vaccines were used simultaneously without any interference in two different studies (Trotta et al. 2015; Çokçalışkan et al. 2019). Live attenuated Brucella and FMD vaccines in cattle were used simultaneously and researchers declared that the antibody titers against Brucella were higher during the simultaneous administration (Hancı 2016 ).

The result of present study can be explained as the development of the interference, depressed or exhausted immunity from the classical immunological point of view (Castenada et al. 1976; Ruben et al 1973; Berger 1988; Vidor 2007; Yi 2010; Kenney et al. 2015). Since a live vaccine can not replicate in the organism when the other live vaccine agent and/or agents have already started the replication (Boikos et al. 2017). A few researchers mentioned another factor is that the cross-reactive epitopes between the vaccine antigens during the vaccine co-administration (Dagan et al. 1998; Kenney et al. 2015). However, in our study viral antigens of three live vaccines (BTV, PPR, and, SGP) do not belong to the same virus family and thus, there are not any cross-reactive epitopes shared between these three viruses.

Simultaneous vaccine administration are very similar to a coinfection due to the exposure of different antigens at the same time (Kenney et al. 2015). Kenney was evaluated T cell memory response during a simultaneous coinfection in laboratory mice. The researchers show that some of the coinfected mice have sufficiently altered memory $T$ cell responses, this change was related to decreasing the protection and overwhelming infection and they reported that a better understanding of the human $\mathrm{T}$ cell response to vaccination is required to optimize immunization strategies in general means. As suggested in Kenney's study, detailed future cellular immunity researches are necessary with the simultaneous vaccine practice, especially in live-live vaccine combinations for animal diseases.

\section{Conclusion}

In conclusion, the simultaneous administration of FMD, SGP, PPR and, BTV vaccines negatively affects the immune response of sheep. Thus, it was reported that these four vaccines can not be administrated simultaneously in sheep. It should be better to start investigating FMD-SGP-PPR or FMD-SGP-BTV coadministration or combined formulation of vaccine agents. It would be better to design a new vaccines 
and future detailed immune response studies are required with more animal numbers and different species for this purpose.

\section{Declarations}

\section{Acknowledgments}

This study was supported by Foot-and-Mouth Disease Institute, Ankara. All animal experiments was conducted in Pendik Veterinary Research Institute, İstanbul. The authors wish to thank Burak Güngör, Hakan Enül, Cumhur Adiay, Sedat Kılıç, Neşe Kalya, Ayşe Parmaksız for their help.

\section{Funding}

This work was supported the FMD- SAP Intitute and Pendik Central Veterinary Research Institute.

\section{Conflict of interest}

The authors declare that they have no conflict of interest.

\section{Ethics approval}

The animal experiments were conducted according to the recommendations in the International Harmonization of Animal Care and Use guidelines (Ethical Committe Decision Number 17/03-1).

\section{Consent to participate}

All authors have consented to publication.

\section{Consent to publication}

All authors have approved to publish.

\section{Data avaiability}

The data sets analyzed during the currect study are available from the corresponding author upon reasonable request.

\section{Code availability}

Not applicable.

\section{Authors' contribution}

BS planned the study, wrote the manuscript, conducted the laboratory test, and data evaluation. VG planned the study and data evaluation. FS coordinated the animal vaccination part of the study. SU 
participated in the animal experiments and tests. ÖK cordinated the PPR and BT tests. CÇ, CG, and EAU participated in the VNT test of FMDV samples. OC contribituted to the statistical analysis.

\section{References}

Berger, R., Just, M., Gluck, R., 1988. Interference between strains in live virus vaccines, I: Combined vaccination with measles, mumps and rubella vaccine, Journal of Biological Standart, 16 (4), 269-273.

Boikos, C., Papenburg, J.C., Joseph, L., Scheifele, D., Chilvers, M., 2017. Viral interference and the liveattenuated intranasal influenza vaccine: Results from a pediatric cohort with cystic fibrosis, Human Vaccine Immunother, 13, 6.

Carey, V.J., Generalized Estimation Equation Solver. In: R Package Version 4. UK: rdrr.io. 2015. https://CRAN.R-project.org/package=gee.

Castaneda, J., Espinoza, M., Bernel, C., Jimenez, J., Aguirre L., 1976. Simultaneous vaccination of cattle with against foot and mouth disease and stomatitis live virus vaccines, Developments in Biological Standardization, 35, 429-36.

Çokçalıskan, C., Göktuna, P.T., Türkoğlu, T., Uzunlu, E., Gündüzalp, C., Aras Uzun, E., Sareyyüpoğlu, B., Kürkçü, A., Gülyaz, V. 2019. Effect of simultaneous administration of foot-and-mouth disease (FMD) and anthrax vaccines on antibody response to FMD in sheep, Clinical Experimental Vaccine Research, 8, 103109.

Dagan, R., Eskola, J., Leclerc, C., Leroy, O., 1998. Reduced response to multiple vaccines sharing common protein epitopes that are administered simultaneously to infants, Infection and Immunity, 66, 2093-8.

De Clercq, K., Strobbe, R., Van Opdenbosch, E., Wellemans, G., Theys, H., Debecq, J., 1989b. The serological response to foot-and-mouth disease vaccination is not affected by simultaneous infectious bovine rhinotracheitis/adenovirus/parainfluenza 3 vaccination, Archiv für Experimentale Veterinaermedizin, 43, 409-413.

De Clercq, K., Koenen, F., Strobbe, R., Debecq, J., 1989a . Simultaneous vaccination of piglets against footand-mouth disease and classical swine fewer. Veterinary Microbiology, 20, 215-221.

Fox, C.B., Kramer, R.M., Banes, V.C., Dowling, Q.M., Vedvick, T.S., 2013. Working together: interactions between vaccine antigens and adjuvants, Therapeutic Advances in Vaccines, 1, 7-20.

Friebe, A., Siegling, A., Friederichs, S., Volk, H.D., Weber, O., 2004. Immunomodulatory effects of inactivated parapoxvirus ovis (ORF virus) on human peripheral immune cells, Journal of Virology, 78, 9400-9411.

Gülyaz, V., Saraç, F., Çokçalışkan, C., Satır, E., Sareyyüpoğlu, B., Arslan, A., Uzar, S., Karakaya, M., Kara, O., Öztap, G., 2019. Determination of the effect of ecthyma vaccine virus on immunity against the foot and 
mouth disease (Fmd) vaccine in sheep, Journal of Animal Health and Production, 8:19-26.

Hamblin, C., Barnett, I.T.R., Hedger, R.S., 1986. A new enzyme-linked immunoassay (ELISA) for the detection of antibodies against Foot and Mouth Disease Virus I. Development and method of ELISA, Journal of Immunological Methods, 93, 115-121.

Hancı, İ., Gürcan, S., Sönmez, A., 2016. The effect of simultaneous application of Brucella and FMD vaccines on antibody level in cattle and sheep, Journal of Etlik Veterinary Microbiology, 27, 27-37.

Hedger, R.S., Taylor, W.P., Barnett, I.T., Reik R., Harpham D, 1986. Simultaneous vaccination of cattle against foot-and-mouth disease and rinderpest, Tropical Animal Health and Production, 18, 21-25.

Joseph, P.G., Hedger, R.S., 1984. Serological response of cattle to simultaneous vaccinations against foot and mouth disease and haemorrhagic septicaemia, Veterinary Record, 114, 494-496.

Kenney, L.L., Cornberg, M., Chen, A.T., Emonet, S., De la Torre, J.C., Selin, L.K., 2015. Increased immune response variability during simultaneous viral coinfection leads to unpredictability in CD8 T cell immunity and pathogenesis. Journal of Virology, 89, $10786-10801$.

Khorasani, A., Madadgar, O., Soleimanjahi, H., Keyvanfar, H., Mahravani, H. 2016. Evaluation of the efficacy of a new oil-based adjuvant ISA 61 VG FMD vaccine as a potential vaccine for cattle, Iran Journal Veterinary Research, 17(1), 8-12.

Kitching, R.P., 1986. The control of sheep and goatpox. Revue Scientifique et Technique (International Office of Epizootics, 5, 501-514.

Kristensen, C.S., Kvisgaard, L.K., Pawlowski, M., Carlsen, S.H,. Hjulsager, C.K., Heegaard, P.M.H,. Bøtner, A., Stadejek, T., Haugegaard, S., Larsen, L.E., 2018. Efficacy and safety of simultaneous vaccination with two modified live virus vaccines against porcine reproductive and respiratory syndrome virus types 1 and 2 in pigs, Vaccine, 36, 227-236.

Maclachlan, N.J., 2011. Bluetongue: history, global epidemiology, and pathogenesis. Preventive Veterinary Medicine, 102, 107-111.

OIE (2021). https://www.oie.int/en/animal-health-in-the-world/animaldiseases/Foot-and-mouth-disease.

OIE (2021). https://www.oie.int/app/uploads/2021/03/bluetongue.pdf

OIE (2021). https://www.oie.int/app/uploads/2021/03/peste-des-petits-ruminants.pdf

OIE (2021). https://www.oie.int/app/uploads/2021/03/sheep-goat-pox.pdf

Özkul, A., Akça, Y., Alkan, F., Barrett, T., Karaoğlu, T., Dağalp, S.B., Anderson, J., Yeşilbağ, K., Çokçalışkan, C., Gençay, A., Burgu I.., 2002. Prevalence, distribution and host range of pste des petits ruminants virus, Turkey, Emerging Infectious Disease, 8, 7. 
Perry, B.D., Rich, K.M., 2007. Poverty impacts of foot-and-mouth disease and the poverty reduction implications of its control. Veterinary Record, 160, 238-241.

Ruben, F.L., Smith, E.A., Foster, S.O., Casey, H.L., Pifer, J.M., 1973. Simultaneous administration of smallpox, measles, yellow fever, and diphtheria-pertussis-tetanus antigens to Nigerian children. Bulletin of the World Health Organization, 48, 175-181.

Saegerman, C., Berkvens, D., Mellor, P.S., 2008. Bluetongue epidemiology in the European Union, Emerging Infectious Disease, 14(4), 539-44.

Sørensen, K.G., Madsen, E.S., Salt, J.S., Njindi, J., Mackay, D.K., 1998. Differentiation of infection from vaccination in foot-and-mouth disease by the detection of antibodies to the non-structural proteins 3D, $3 A B$ and $3 A B C$ in ELISA using antigens expressed in baculovirus, Archives Virology, 143, 1461-76.

Srinivasan, V.A., Villuppanoor, A., Srinivasan R.G., Rao, K.A., Kihm, U., 2001. Serological response of bovines to combined vaccine containing foot and mouth disease virus, rabies virus, pasteurella multocida and clostridium chauvoei antigens, Veterinarski Arhiv, 71, 37-45.

Tizard, I., 2017. Veterinary Immunology, (Saunders, USA)

Tizart I., 1990. Risks associated with use of live vaccines, Journal of the American Veterinary Medical Association, 196:1851-8.

Trotta, M., Lahore, J., Cardoso, N., Melucci, O., Catena, M., Pérez-Filgueira, M., Fernández, F., Capozzo, A.V., 2015. Simultaneous immunization of cattle with foot-and-mouth disease (FMD) and live anthrax vaccines do not interfere with FMD booster responses. Trials in Vaccinology, 4, 38-42.

Vidor, E., 2007. The nature and consequences of intra- and inter-vaccine interference. Journal Comparative Pathology 137(Suppl 1), 62-66.

Yi, J.S., Cox, M.A., Zajac, A., 2010. T-cell exhaustion, characteristics, causes, conversion, Immunology, 129, 474-481

\section{Figures}


Fig 1a. Simultaneous and single vaccinations mean antibody titers for FMDV, VN $\log ^{10}, 60 \mathrm{DPV}$

3

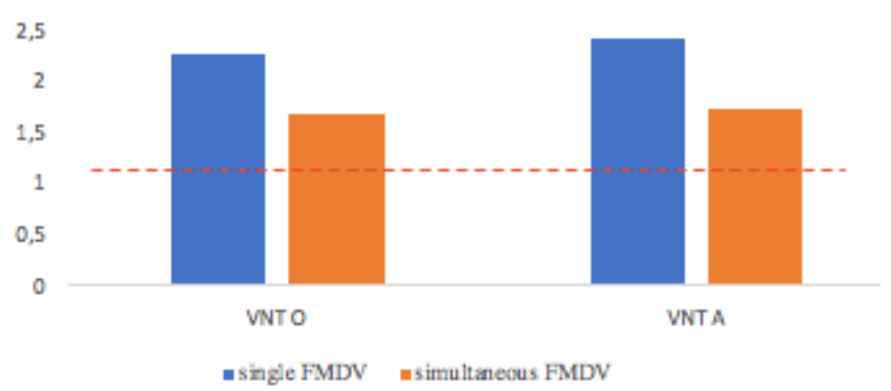

Fig 1c. Simultaneous and single vaccinations, mean antibody titers, VNT, PPR, 60DPV

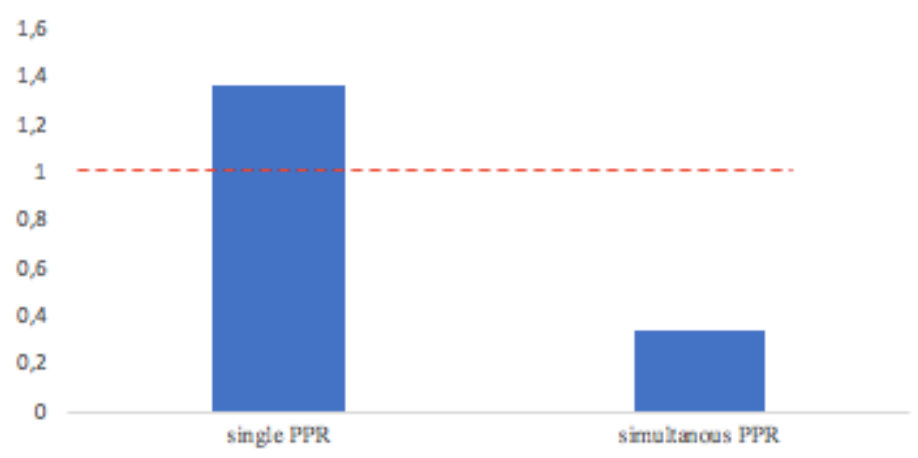

Fig 1b. Simultaneous and single vaccinations mean antibody titers for FMDV, LPBE $\log ^{10}, 60 \mathrm{DPV}$

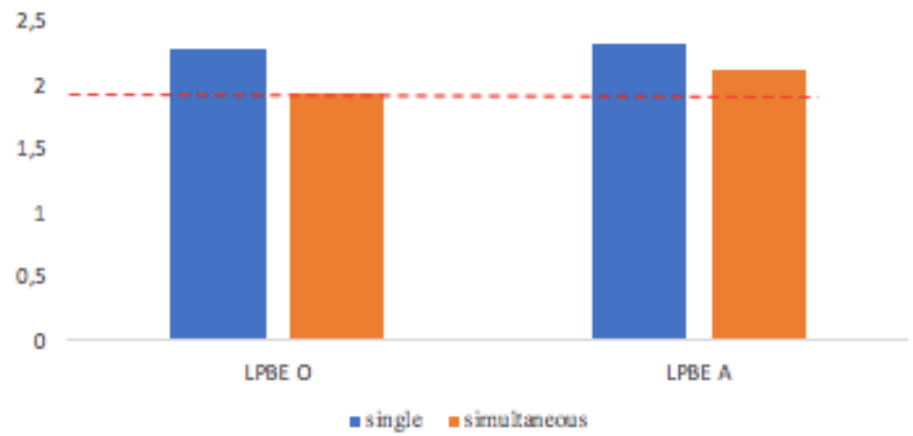

Fig 1d. Simultaneous and single vaccinations, mean antibody titers, VNT, BTV, 60DPV

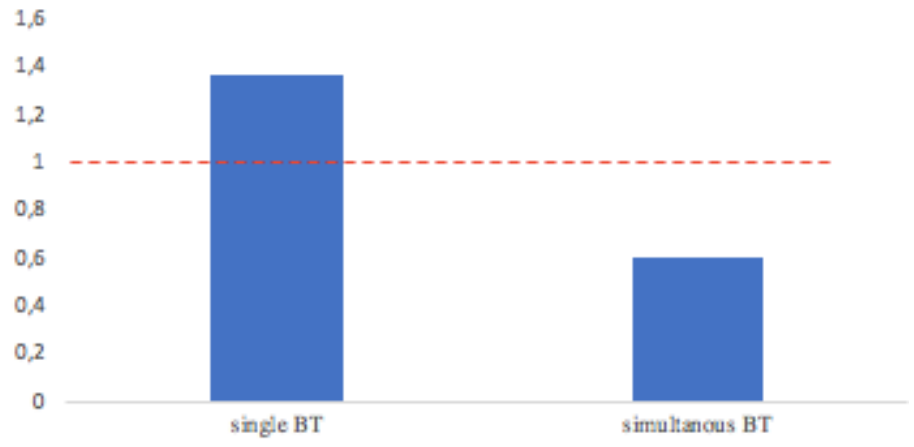

\section{Figure 1}

See image above for figure legend. 